\title{
Perbandingan Karakteristik Pengujian Marshall Campuran Aspal Beton Dengan Filler Pasir Besi Dan Abu Batu
}

\author{
Hery Awan Susanto ${ }^{1}$ \\ 'Jurusan Teknik Sipil, Fakultas Teknik, Universitas Jenderal Soedirman 53371 \\ Email: hery.susanto@unsoed.ac.id
}

\begin{abstract}
ABSTRAK
Pembangunan jalan dengan perkerasan lentur terus meningkat dari tahun ke tahun, sedangkan ketersediaan material penyusun terus berkurang. Aspal dan agregat adalah material alam yang tidak bisa diperbaharui, sehingga pada suatu saat akan habis. Agregat juga mengalami perubahan bentuk dan kualitas akibat pengaruh iklim. Oleh karena itu perlu dilakukan penelitian terhadap penggunaan agregat alternatif. Pemanfaatan agregat alternatif akan lebih ekonomis dan efisien jika memanfaatkan potensi lokal. Salah satu potensi agregat yang melimpah di Selatan Pulau Jawa adalah pasir besi. Pemanfaatan pasir besi dalam campuran beraspal saat ini masih terbatas sebagai agregat halus. Oleh karena itu penelitian ini bertujuan untuk menyelidiki pemanfaatan pasir besi sebagai pengganti filler dalam campuran beraspal. Penelitian ini juga bertujuan untuk membandingkan kinerja campuran aspal beton menggunakan filler pasir besi dan abu batu dengan pengujian Marshall di laboratorium. Dari hasil penelitian diketahui bahwa berat jenis campuran filler pasir besi $9 \%$ lebih tinggi dibandingkan dengan abu batu. Nilai stabilitas filler pasir besi 16,5\% dan Marshall Quotient 44,7\% lebih tinggi dibandingkan dengan filler abu batu. Oleh karena itu filler pasir besi mampu menahan beban lalu lintas yang lebih baik dibandingkan filler abu batu. Penambahan filler pasir besi juga berdampak pada peningkatan elastisitas struktur asphalt concrete-wearing course (AC-WC), sehingga struktur perkerasan menjadi lebih kaku. Disisi lain campuran dengan filler pasir besi membuat struktur perkerasan rentan terjadinya raveling.
\end{abstract}

Kata kunci: Agregat, Filler, Pasir Besi, Abu Batu, AC-WC, Pengujian Marshall

\begin{abstract}
The construction of flexible pavement continues to increase, while the availability of asphalt materials continues to decrease. Asphalt and aggregate are un-renewable materials, thus someday will run out. The aggregates also change in shape and quality due to climate change. Therefore, it is necessary to conduct research on the use of alternative aggregates. Utilization of alternative aggregates will be more economical and efficient if it utilizes local potential. One of the abundant aggregate potentials in South Java Island is iron sand. Utilization of iron sand in asphalt mixtures is currently still limited as a fine aggregate. Therefore, this study aims to investigate the use of iron sand as a substitute for filler in asphalt mixtures. This study also aims to compare the performance of asphalt concrete mix using iron sand and stone ash filler with Marshall testing in the laboratory. The result shows that the specific gravity of the iron sand filler mixture is $9 \%$ higher than that of stone ash. The stability value of iron sand filler is 16,5\% and Marshall Quotient (MQ) is 44,7\% higher than stone ash filler. The addition of iron sand filler also has an impact on increasing the elasticity of the asphalt concrete-wearing course (AC-WC), thus effect to more rigid. On the other hand, the mixture with iron sand filler makes the pavement structure vulnerable to raveling.
\end{abstract}

Keywords: Aggregate, Filler, Iron Sand, Stone Ash, AC-WC, Marshall Test

\section{PENDAhuluan}

Campuran aspal beton adalah jenis lapisan konstruksi jalan dengan bahan penyusun aspal dan agregat [1]. Tipe aspal beton yang dipakai umumnya adalah aspal penetrasi 60/70 atau 80/100. Sedangkan untuk agregat terdiri dari agregat kasar, halus, dan filler yang membentuk gradasi baik [2]. Proses pencampuran aspal dan agregat dilakukan pada suhu tertentu sesuai jenis lapisan perkerasan. Untuk jenis hot mix asphalt (HMA) suhu pencampuran aspal dan agregat berkisar $140-160{ }^{\circ} \mathrm{C}[3,4]$.

Dalam campuran aspal beton penggunaan filler berfungsi sebagai bahan pengisi di antara agregat kasar dan halus sehingga tidak terdapat rongga. Filler juga memberikan pengaruh terhadap kinerja campuran beraspal meliputi: weathering, durability, bleeding, dan pliability. Pemilihan filler dalam campuran beraspal harus kering, bersih, dan elastis [5,6]. Filler juga harus memiliki kadar air yang cukup, sehingga menghasilkan lapisan beton aspal yang kedap air [7].

Kualitas campuran aspal beton salah satunya dipengaruhi oleh ketersediaan material yang memenuhi spesifikasi teknis. Sumber material yang dekat dengan lokasi proyek juga akan menurunkan biaya konstruksi jalan. Saat ini abu batu (stone ash) banyak digunakan sebagai filler campuran beraspal. Namun demikian beberapa peneliti telah berhasil melakukan studi tentang penggunaan filler alternatif seperti: abu terbang (fly ash), kapur, abu sekam padi, semen, batu bata, dan abu sawit dalam campuran beraspal [8]. 
Pemanfaatan bahan filler alternatif berdasarkan potensi sumber daya lokal terus dikaji untuk menekan biaya pembangunan konstruksi jalan. Salah satu potensi lokal yang melimpah di pesisir pantai Selatan Pulau Jawa adalah pasir besi dengan jumlah produksi hampir mencapai $60 \%$. Karakteristik yang dimiliki oleh pasir besi yaitu memiliki tekstur yang kasar dan berat jenis tinggi, sehingga mampu meningkatkan koefisien gesek permukaan perkerasan dan menurunkan kadar aspal dalam campuran beraspal.

Studi pemanfaatan pasir besi dalam campuran beraspal yang digunakan sebagai agregat halus mampu menunjukkan peningkatan stabilitas dan penurunan flow [9]. Hal ini dikarenakan kandungan besi (Fe) pada pasir besi yang mampu meningkatkan kekuatan pasir besi itu sendiri dan berdampak pada peningkatan kekuatan struktur jalan. Pemanfaatan pasir besi masih terbatas sebagai pengganti agregat halus saja [10]. Belum ada penelitian yang melakukan studi pemanfaatan pasir besi sebagai filler dalam campuran beraspal. Oleh karena itu dengan melihat potensi pasir besi yang besar di Kabupaten Cilacap dan dengan kadar Fe yang tinggi, maka perlu dilakukan penelitian pemanfaatan pasir besi sebagai filler dalam campuran beraspal.

Tujuan dari penelitian ini adalah untuk menyelidiki pemanfaatan pasir besi sebagai pengganti filler dalam campuran beraspal. Penelitian ini juga bertujuan untuk membandingkan kinerja campuran aspal beton menggunakan filler pasir besi dan abu batu.

\section{MATERIAL DAN METODOLOGI}

Tahapan pengujian dilakukan untuk mendapatkan hasil pengujian sesuai dengan tujuan yang ingin dicapai dalam penelitian ini. Perbandingan kinerja aspal beton dengan menggunakan filler pasir besi dan abu batu ditentukan melalui pengujian Marshall di laboratorium [11,12]. Tahapan pengujian dimulai dengan menyiapkan material penyusun aspal beton, pengujian karakteristik material, pembuatan sampel Marshall, penentuan kadar aspal optimum (KAO), pengujian Marshall berdasarkan nilai KAO [13].

\subsection{Pengujian Material di Laboratorium}

Dalam penelitian ini dipilih campuran aspal beton jenis asphalt concrete-wearing course (AC-WC), karena lapisan ini adalah lapisan teratas yang secara langsung mendapatkan beban lalu lintas kendaraan. Selanjutnya aspal penetrasi tipe 60/70 dipilih dengan pertimbangan aspal tipe ini sering digunakan dalam pembuatan jalan di Indonesia. Pengujian sifat fisik aspal harus memenuhi standar Bina Marga [7]. Material agregat kasar, halus, dan abu batu diperoleh dari PT. Sambas Wijaya, Purbalingga. Sedangkan untuk filler pasir besi diperoleh dari penambangan tradisional di Kecamatan Adipala, Kabupaten Cilacap. Karakteristik agregat yang digunakan harus memenuhi standar pengujian dari Bina Marga [7]. Gradasi agregat gabungan harus dikontrol agar memenuhi spesifikasi yang telah ditentukan. Untuk mengetahui persentase rongga di antara agregat dan dalam campuran AC-WC dilakukan pengujian berat jenis filler.

Tabel 1Tabel 4 menunjukkan spesifikasi pengujian aspal dan agregat untuk campuran beton aspal berdasarkan standar Bina Marga. Sedangkan Gambar 1 adalah gradasi agregat gabungan yang harus dicapai untuk mendapatkan campuran AC-WC [7].

Tabel 1. Spesifikasi Pengujian Aspal Penetrasi

\begin{tabular}{cc}
\hline Pengujian & Spesifikasi \\
\hline Penetrasi pada $25^{\circ} \mathrm{C}(\mathrm{dmm})$ & $60-70$ \\
\hline Titik Lembek $\left({ }^{\circ} \mathrm{C}\right)$ & Min. 48 \\
\hline Titik Nyala $\left({ }^{\circ} \mathrm{C}\right)$ & Min. 232 \\
\hline Daktilitas pada $25^{\circ} \mathrm{C}$ & Min. 100 \\
\hline Berat Jenis & Min. 1 \\
\hline Indeks penetrasi & Min. -1 \\
\hline Kelarutan dalam Toluene $(\%)$ & Min. 99 \\
\hline Pengujian hasil residu hasil TFOT \\
\hline Berat yang hilang $($ TFOT $), \%$ berat & Max. 0.8 \\
\hline Penetrasi pada $25^{\circ} \mathrm{C}(\mathrm{dmm})$ & Min. 54 \\
\hline Daktilitas pada $25^{\circ} \mathrm{C}(\mathrm{cm})$ & Min. 100 \\
\hline Indeks penetrasi & Min. -1 \\
\hline
\end{tabular}


Tabel 2. Spesifikasi Pengujian Agregat Kasar

\begin{tabular}{cc}
\hline Pengujian & Spesifikasi \\
\hline Kekekalan bentuk agregat & Maks. 12\% \\
\hline Abrasi & Maks. 30\% \\
\hline Kelekatan agregat terhadap aspal & Min. 95\% \\
\hline Angularitas (kedalaman $<10 \mathrm{~cm}$ ) & $95 / 90$ \\
\hline Angularitas (kedalaman $\geq 10 \mathrm{~cm}$ ) & $80 / 75$ \\
\hline Partikel pipih dan lonjong & Maks. 10 \% \\
\hline Material lolos ayakan No. 200 & Maks. 1\% \\
\hline
\end{tabular}

Tabel 3. Spesifikasi Pengujian Agregat Halus

\begin{tabular}{cc} 
Pengujian & Spesifikasi \\
\hline Nilai setara pasir & Min. 70\% \\
\hline Material lolos ayakan No. 200 & Maks. 8\% \\
\hline Angularitas (kedalaman $<10 \mathrm{~cm}$ ) & Min. 45 \\
\hline Angularitas (kedalaman $\geq 10 \mathrm{~cm}$ ) & Min. 40 \\
\hline Kadar lempung & $1 \%$ \\
\hline
\end{tabular}

Tabel 4. Spesifikasi Pengujian Filler

\begin{tabular}{cc}
\hline Pengujian & Spesifikasi \\
\hline Lolos saringan No.200 & $\geq 75 \%$ \\
\hline
\end{tabular}

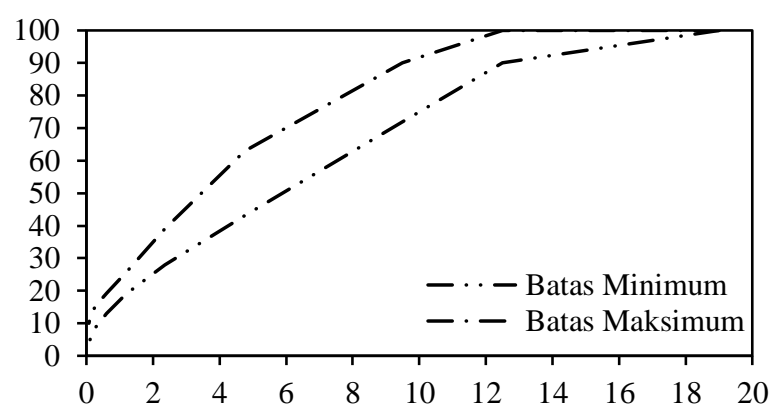

Gambar 1. Spesifikasi Gradasi Agregat Gabungan

\subsection{Analisis Perbandingan Kinerja Hasil Pengujian Marshall}

Setelah material memenuhi semua spesifikasi yang berlaku, maka dilakukan pembuatan sampel Marshall untuk mencari nilai KAO dengan filler abu batu. Penentuan awal nilai KAO dilakukan dengan menggunakan persamaan empiris pada persamaan (1) [7].

$$
\mathrm{Pb}=0,035(\% \mathrm{CA})+0,045(\% \mathrm{FA})+0,18(\% \mathrm{FF})+\mathrm{K}
$$

keterangan;

$P b=$ Perkiraan kadar aspal terhadap campuran; persentase berat terhadap campuran (\%)

$\mathrm{CA}=$ Coarse Agregate; Agregat kasar tertahan saringan No. $8(2,36 \mathrm{~mm})$

FA=Fine Agregate; Agregat halus lolos saringan No. 8 (2,36 mm)

$\mathrm{FF}=$ Fine Filler; bahan pengisi lolos saringan No. $200(0,075 \mathrm{~mm})$

$\mathrm{K}=$ Konstanta; untuk laston AC-WC dipakai 0,5-1,0

Sampel untuk mencari nilai KAO dibuat masing-masing berjumlah 3 buah sesuai Tabel 5. Ketentuan nilai kadar aspal pendekatan dilakukan berdasarkan nilai $\mathrm{Pb}$, yaitu: $(\mathrm{Pb}-1 \%),(\mathrm{Pb}-0,5 \%), \mathrm{Pb},(\mathrm{Pb}+0,5 \%)$, dan $(\mathrm{Pb}+1 \%)[7]$. 
Tabel 5. Jumlah Sampel Marshall untuk mencari KAO

\begin{tabular}{cccccc}
\hline \multirow{2}{*}{ Jenis Filler } & \multicolumn{5}{c}{ Variasi Kadar Aspal } \\
\cline { 2 - 6 } & $\mathbf{- 1 \%}$ & $\mathbf{- 0 , 5 \%}$ & $\mathbf{P b}$ & $\mathbf{+ 0 , 5 \%}$ & $\mathbf{+ 1 \%}$ \\
\hline Abu Batu & 3 & 3 & 3 & 3 & 3 \\
\hline
\end{tabular}

Setelah mendapatkan nilai $\mathrm{KAO}\left(\mathrm{Pb}_{\mathrm{opt}}\right)$, maka dilakukan pengujian Marshall aspal beton dengan filler abu batu dan pasir besi sesuai Tabel 6 .

Tabel 6. Jumlah Sampel Marshall dengan KAO

\begin{tabular}{cc}
\hline Jenis Filler & KAO \\
\hline Abu batu & 3 \\
\hline Pasir besi & 3
\end{tabular}

Selanjutnya dari hasil pengujian tersebut di atas, maka bisa dilakukan analisis perbandingan kinerja aspal beton dengan 2 jenis filler, yaitu abu batu dan pasir besi. Gambar 2 adalah diagram alur penelitian yang digunakan untuk mencapai tujuan dari penelitian ini. Parameter pengujian Marshall meliputi nilai volumetrik dan nilai Marshall. Nilai volumetrik terdiri dari density (Gr/mm), Voids in Mix (VIM:\%), Voids in Mineral Agregate (VMA:\%), Voids Filled Bitumen (VFB:\%). Sedangkan nilai Marshall terdiri dari stabilitas (Kg), flow (mm), dan Marshall Quotient (MQ: Kg/mm).

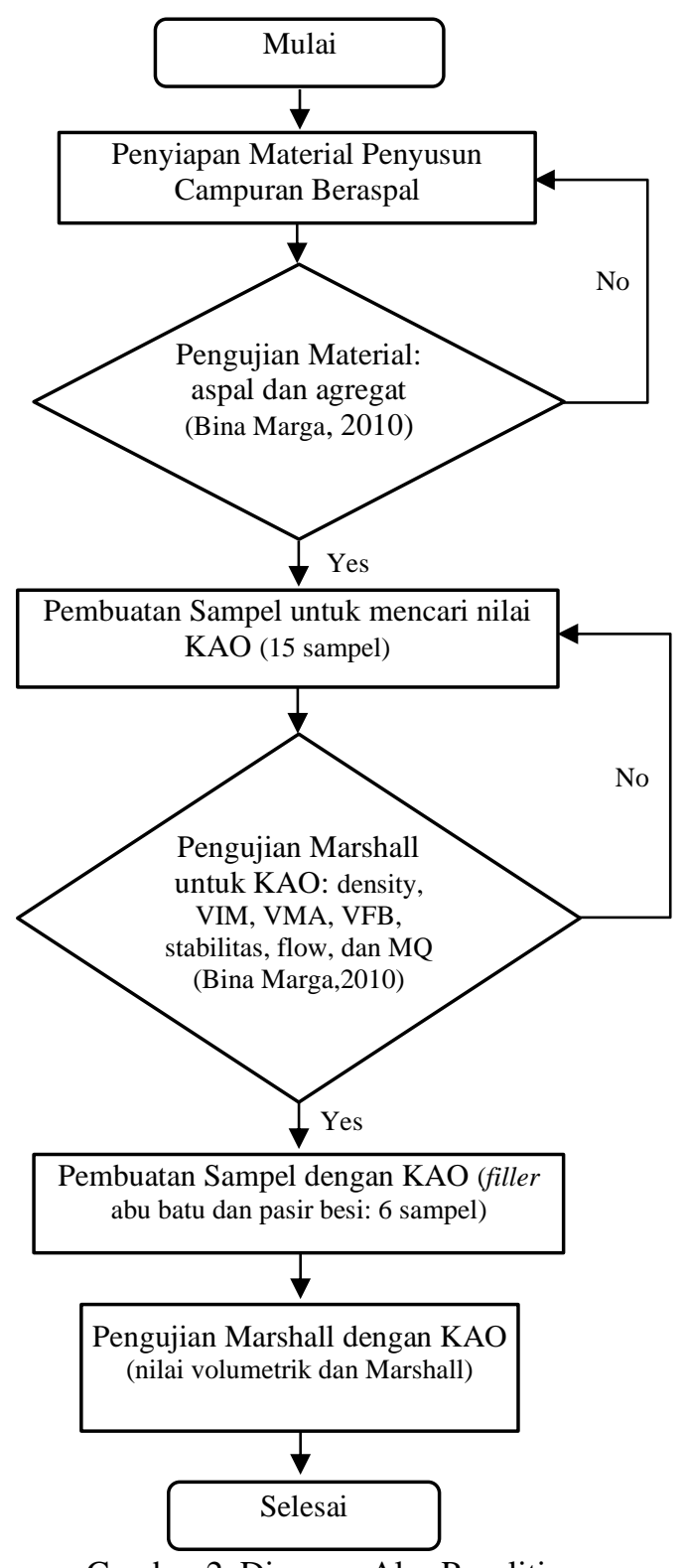

Gambar 2. Diagram Alur Penelitian 


\section{HASIL DAN PEMBAHASAN}

\subsection{Karakteristik Material Asphalt Concrete Wearing Course}

Hasil pengujian karakteristik material ditampilkan dari mulai Tabel 7Tabel 10. Sedangkan Gambar 3 menunjukkan gradasi agregat gabungan dari hasil pengujian sieve analysis. Dari data hasil pengujian dapat diketahui bahwa material yang dipakai memenuhi standar yang ditentukan oleh Bina Marga. Aspal penetrasi 60/70 yang dipakai dalam campuran beraspal telah memenuhi semua kriteria sifat rheologi aspal sesuai spesifikasi Bina Marga dalam Tabel 1. Sehingga aspal penetrasi 60/70 dapat digunakan dalam campuran beraspal. Hasil pengujian aspal penetrasi 60/70 terangkum dalam Tabel 7. Demikian pula dengan agregat kasar, halus, dan filler berdasarkan hasil pengujian yang dilakukan telah memenuhi semua spesifikasi seperti yang disyaratkan oleh Bina Marga dalam Tabel 2-4. Sehingga agregat yang dipilih dapat digunakan dalam campuran beraspal. Hasil pengujian agregat ditampilkan dalam Tabel 8-10. Tabel 11 menunjukkan hasil pengujian berat jenis filler antara pasir besi dan abu batu. Berat jenis pasir besi lebih tinggi daripada berat jenis abu batu. Berdasarkan nilai volumetrik, maka berat jenis yang tinggi akan berdampak pada density yang lebih tinggi dan efisiensi berat material.

Tabel 7. Hasil Pengujian Aspal Penetrasi 60/70

\begin{tabular}{cc}
\hline Pengujian & $\begin{array}{c}\text { Hasil } \\
\text { Pengujian }\end{array}$ \\
\hline Penetrasi pada $25^{\circ} \mathrm{C}(\mathrm{dmm})$ & 66 \\
\hline Titik Lembek $\left({ }^{\circ} \mathrm{C}\right)$ & $56,7^{\circ} \mathrm{C}$ \\
\hline Titik Nyala $\left({ }^{\circ} \mathrm{C}\right)$ & $322^{\circ} \mathrm{C}$ \\
\hline Daktilitas pada $25^{\circ} \mathrm{C}$ & $>110 \mathrm{~cm}$ \\
\hline Berat Jenis & $1,042 \mathrm{gr} / \mathrm{cc}$ \\
\hline Indeks penetrasi & 1,19 \\
\hline Kelarutan dalam Toluene $(\%)$ & $99,3 \%$ \\
\hline Pengujian hasil residu hasil TFOT \\
\hline Berat yang hilang $($ TFOT $), \%$ berat & $0,28 \%$ \\
\hline Penetrasi pada $25^{\circ} \mathrm{C}(\mathrm{dmm})$ & 65,8 \\
\hline Daktilitas pada $25^{\circ} \mathrm{C}(\mathrm{cm})$ & $>110 \mathrm{~cm}$ \\
\hline Indeks penetrasi & 1,17 \\
\hline
\end{tabular}

Tabel 8. Hasil Pengujian Agregat Kasar

\begin{tabular}{cc}
\hline Pengujian & Hasil Pengujian \\
\hline Kekekalan bentuk agregat & $3,132 \%$ \\
\hline Abrasi & $29,80 \%$ \\
\hline Kelekatan agregat terhadap aspal & $98,00 \%$ \\
\hline Angularitas $(<10 \mathrm{~cm})$ & $94.70 \%$ \\
\hline Angularitas ( $\geq 10 \mathrm{~cm})$ & - \\
\hline Partikel pipih dan lojong & $8,46 \%$ \\
\hline Material lolos ayakan No. 200 & $0,67 \%$ \\
\hline
\end{tabular}

Tabel 9. Hasil Pengujian Agregat Halus

\begin{tabular}{cc}
\hline Pengujian & Hasil Pengujian \\
\hline Nilai setara pasir & $70,85 \%$ \\
\hline Material lolos ayakan No. 200 & $6,672 \%$ \\
\hline Angularitas (kedalaman $<10 \mathrm{~cm}$ ) & $93,32 \%$ \\
\hline Angularitas (kedalaman $\geq 10 \mathrm{~cm}$ ) & $93,23 \%$ \\
\hline Kadar lempung & $0,98 \%$ \\
\hline
\end{tabular}


Tabel 10. Hasil Pengujian Filler

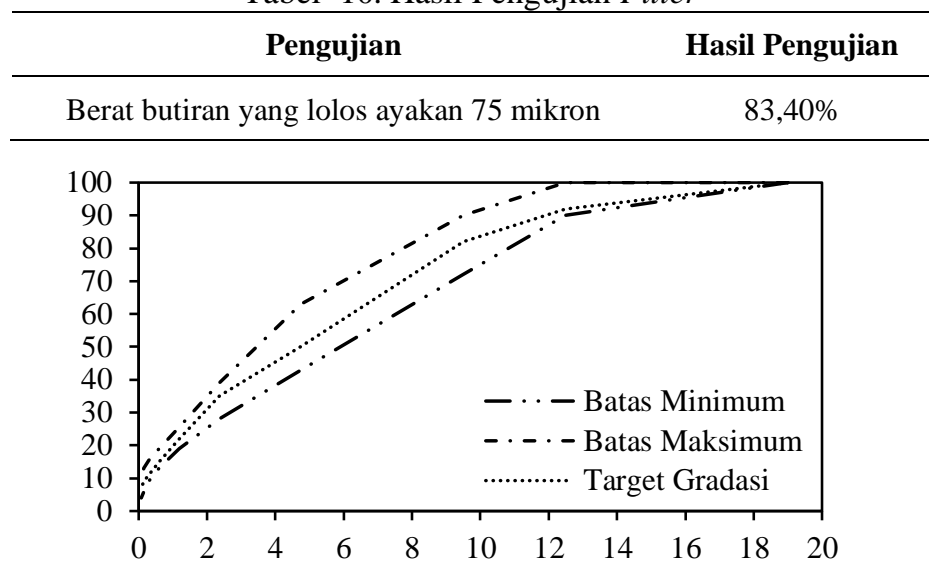

Gambar 3. Gradasi Agregat Gabungan Hasil Analisa Saringan

Tabel 11. Hasil Pengujian Berat Jenis Filler

\begin{tabular}{cccc}
\hline Persentase Filler & BJ Bulk & BJ Apparent & BJ Efektif \\
\hline Abu batu & 2,608 & 2,736 & 2,672 \\
\hline Pasir besi & 2,829 & 3,011 & 2,924 \\
\hline
\end{tabular}

\subsection{Hasil Pengujian Marshall untuk Menentukan KAO}

Tabel 12 Tabel 13 menunjukkan proses penentuan nilai KAO. Tabel 12 adalah hasil pengujian Marshall untuk mencari nilai KAO. Setelah mendapatkan nilai karakteristik pengujian Marshall, kemudian nilai KAO dicari dengan menggunakan cara pada Tabel 13. Penentuan Nilai KAO.

Tabel 12. Hasil Pengujian Marshall untuk mencari KAO

\begin{tabular}{cccccc}
\hline $\begin{array}{c}\text { Kadar aspal } \\
(\mathbf{\%})\end{array}$ & $\mathbf{3 , 5}$ & $\mathbf{4}$ & $\mathbf{4 , 5}$ & $\mathbf{5}$ & $\mathbf{5 , 5}$ \\
\hline Density $(\mathrm{Gr} / \mathrm{cc})$ & 2,408 & 2,376 & 2,365 & 2,347 & 2,323 \\
\hline VFB $(\%)$ & 60 & 66 & 69 & 76 & 83 \\
\hline VIM $(\%)$ & 5,99 & 4,57 & 4,21 & 3,44 & 2,43 \\
\hline VMA $(\%)$ & 12,3 & 14,78 & 14,84 & 14,99 & 15,01 \\
\hline Stabilitas $(\mathrm{Kg})$ & 826 & 947 & 956 & 977 & 1166 \\
\hline Flow $(\mathrm{mm})$ & 6,83 & 6,3 & 5,99 & 5,45 & 4,91 \\
\hline MQ $(\mathrm{Kg} / \mathrm{mm})$ & 121 & 150 & 160 & 179 & 238 \\
\hline
\end{tabular}

Tabel 13. Penentuan Nilai KAO

\begin{tabular}{|c|c|c|c|c|c|}
\hline \multirow[t]{2}{*}{ Kriteria } & \multirow[t]{2}{*}{ Spesifikasi } & \multicolumn{4}{|c|}{ Kadar aspal (\%) } \\
\hline & & 3,5 & $4 \quad 4,5$ & 5 & 5,5 \\
\hline Density $(\mathrm{Gr} / \mathrm{cc})$ & - & & & & \\
\hline VFB $(\%)$ & Min.65 & & & & \\
\hline VIM (\%) & $3-5,9$ & $\bar{x}$ & & & \\
\hline VMA (\%) & Min.15 & & & & \\
\hline Stabilitas $(\mathrm{Kg})$ & Min.800 & & & & \\
\hline Flow $(\mathrm{mm})$ & Min. 2 & & & & \\
\hline MQ (Kg/mm) & Min. 200 & & & & \\
\hline
\end{tabular}

\subsection{Hasil Pengujian Marshall dengan KAO}

Gambar 4 Gambar 5 menunjukkan hasil pengujian Marshall untuk sampel dengan filler abu batu dan pasir besi dengan nilai KAO 5,5\%. Terlihat dari hasil uji berat jenis sampel AC-WC dengan filler pasir besi sebesar 2,41 Gr/cc, sedangkan filler abu batu sebesar 2,32 Gr/cc. Berat jenis filler pasir besi $9 \%$ lebih tinggi dibandingkan dengan abu batu. Dengan volume yang sama dan berat jenis berbeda, maka kebutuhan material penyusun sampel menjadi berbeda. Hal ini dikarenakan berat jenis efektif pasir besi lebih tinggi daripada abu batu, sehingga campuran dengan filler pasir besi membutuhkan jumlah material penyusun 
yang lebih sedikit. Campuran dengan berat jenis yang besar juga menunjukkan bahwa campuran tersebut memiliki kekuatan yang besar dalam menahan beban lalu lintas.

Dari nilai VFB dapat diketahui bahwa campuran AC-WC dengan filler abu batu sebesar 83\%, sedangkan filler abu batu sebesar $58 \%$. VFB filler abu batu 30,12\% lebih tinggi dibandingkan pasir besi, sehingga campuran AC-WC dengan filler abu batu membutuhkan aspal yang lebih banyak dibandingkan pasir besi. Nilai VFB yang tinggi akan berpotensi terhadap terjadinya bleeding dalam campuran, sehingga harus diantisipasi dengan baik. Sedangkan jika ditinjau dari nilai VIM, maka campuran AC-WC dengan filler pasir besi memiliki nilai 9,36\%, dan filler abu batu 2,43\%. Filler pasir besi memiliki VIM 74,04\% lebih tinggi dibandingkan abu batu. Hal ini berakibat campuran AC-WC dengan filler pasir besi berpotensi terjadinya pelepasan butiran (raveling). Nilai VMA campuran dengan filler pasir besi memiliki VMA sebesar 22,08\%, dan abu batu sebesar $15,01 \%$. VMA filler pasir besi $32,02 \%$ lebih tinggi dibandingkan abu batu. Peningkatan nilai VMA pada filler pasir besi menyebabkan mengecilnya rongga yang terisi aspal.

Dari analisis nilai stabilitas, flow dan MQ dapat diketahui bahwa nilai stabilitas filler pasir besi sebesar $1397 \mathrm{Kg}$, flow 3,25 $\mathrm{mm}$, dan MQ $43 \mathrm{Kg} / \mathrm{mm}$. Sedangkan filler abu batu memiliki nilai stabilitas filler pasir besi sebesar $1166 \mathrm{Kg}$, flow 4,91 mm, dan MQ 23,8 Kg/mm. Dengan demikian maka dapat disimpulkan bahwa nilai stabilitas filler pasir besi sebesar $16,5 \%$ lebih tinggi, flow 33,8 \% lebih rendah, dan MQ 44,7\% lebih tinggi dibandingkan filler abu batu. Dari korelasi ketiga nilai tersebut maka filler pasir besi memberikan sifat struktur AC-WC lebih kaku dibandingkan dengan filler abu batu.

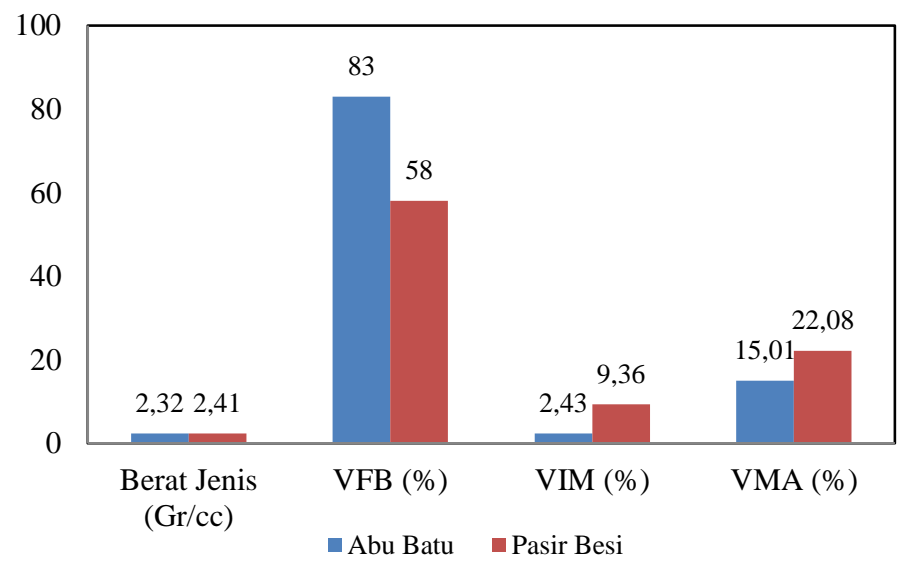

Gambar 4. Perbandingan Kinerja Campuran AC-WC berdasarkan Nilai Volumetrik Pengujian Marshall pada KAO

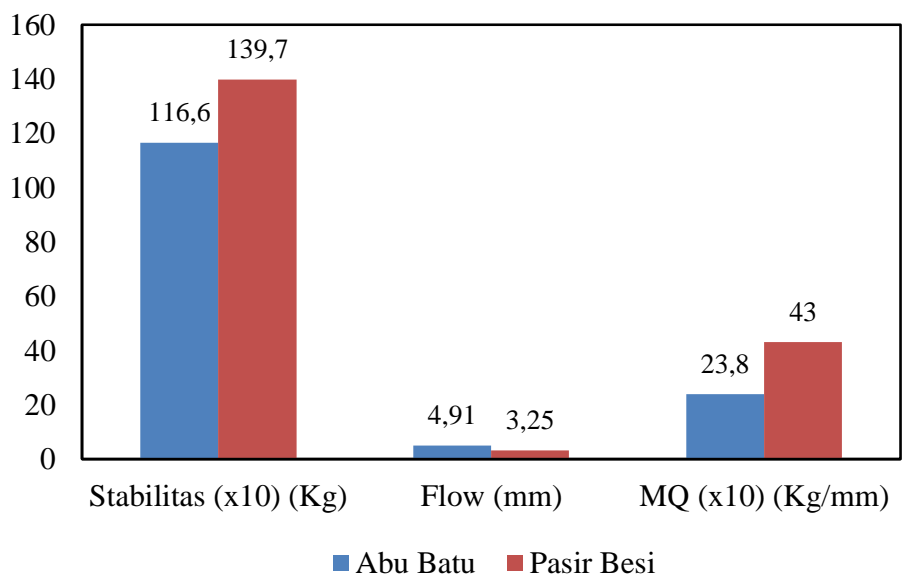

Gambar 5. Perbandingan Kinerja Campuran AC-WC berdasarkan Karakteristik Nilai Marshall pada KAO

\section{KESIMPULAN}

Dalam penelitian ini dilakukan perbandingan kinerja campuran AC-WC dengan filler abu batu dan pasir besi. Dari hasil penelitian ini dapat disimpulkan bahwa:

a) Berat jenis campuran filler pasir besi $9 \%$ lebih tinggi dibandingkan filler abu batu yang berdampak pada kebutuhan berat material yang lebih sedikit, sehingga lebih ekonomis. 
b) Bahwa filler pasir besi memiliki stabilitas 16,5\% dan MQ 44,7\% lebih tinggi dibandingkan filler abu batu, sehingga mampu menahan beban lalu lintas yang lebih baik.

c) Penambahan pasir besi sebagai filler berdampak pengurangan elastisitas struktur AC-WC, sehingga menjadi lebih kaku.

d) Campuran dengan filler pasir besi membuat struktur rentan terhadap raveling, sedangkan campuran dengan filler abu batu rentan terhadap bleeding.

\section{DAFTAR PUSTAKA}

[1] Indraswari H., Bahan Perkerasan Jalan, Direktorat Jenderal Bina Marga, Departemen Pekerjaan Umum, 1971, Jakarta.

[2] Anas T., "Karakteristik Campuran Beton Aspal (AC-WC) Dengan Menggunakan Variasi Kadar Filler Abu Terbang Batu Bara", Jurnal SMARTek, Vol. 7, No. 4, November 2009: 256 - 278.

[3] Sukirman S., Perkerasan Lentur Jalan Raya, 1999, Jakarta: Yayasan Obor Indonesia.

[4] Sukiman S., Beton Aspal Campuran Panas, Buku Obor, 2008, Jakarta.

[5] Sjachril M., Perencanaan Bahan Campuran Aspal, 2008, Pusdiklat Departemen Pekerjaan Umum.

[6] Departemen Pekerjaan Umum, Perencanaan Material Campuran Aspal, Direktorat Jenderal Prasarana Wilayah, 2004, Jakarta.

[7] Bina Marga, Seksi 6.3, Spesifikasi Campuran Beraspal Panas pada Spesifikasi Umum Jalan dan Jembatan Edisi 2010, Jakarta : Direktorat Jendral Bina Marga.

[8] Mulyono, A.T., "Pengaruh Variasi Jenis dan Kadar Filler Terhadap Stabilitas, Fleksibilitas dan Tingkat Durabilitas HRS (Hot Rolled Sheet) Kelas B”, Media Teknik, No.3, Edisi November 1996, UGM, Yogyakarta.

[9] Priambodo A., Kajian Laboratorium Pengaruh Penggunaan Pasir Besi Sebagai Agregat Halus pada campuran Aspal Panas HRA terhadap sifat Marshall dan Durabilitas, Tesis Tidak Diterbitkan, Jurusan Teknik Sipil Universitas Diponegoro, 2003, Semarang. (eprints.undip.ac.id)

[10] Goenarto and Mario, Penggunaan Limbah Pasir Besi sebagai Bahan Campuran Agregat Halus pada Campuran Aspal Beton, Skripsi, Petra Christian University, 2002.

[11] SKNI-M-58-1990-03, Metode Pengujian Campuran Aspal Dengan Alat Marshall, Departemen pekerjaan Umum, 1990, Jakarta.

[12] Bina Marga, RSNI-M-01, Metode Pengujian Campuran Beraspal Panas dengan Alat Marshall, 2003, Jakarta : Pustran Balitbang Pekerjaan Umum.

[13] Indraswari H., Aspal Beton, Perencanaan Campuran Di Laboratorium, Direktorat Jenderal Bina Marga, Departemen Pekerjaan Umum, 1976, Jakarta. 